\title{
"Delirium Day": a nationwide point prevalence study of delirium in older hospitalized patients using an easy standardized diagnostic tool
}

Giuseppe Bellelli ${ }^{1,2,3^{*}}$, Alessandro Morandi ${ }^{3,4}$, Simona G. Di Santo ${ }^{5}$, Andrea Mazzone ${ }^{6}$, Antonio Cherubini ${ }^{7}$, Enrico Mossello ${ }^{8}$, Mario Bo ${ }^{9}$, Angelo Bianchetti ${ }^{10}$, Renzo Rozzini ${ }^{11}$, Ermellina Zanetti ${ }^{2}$, Massimo Musicco ${ }^{12,13}$, Alberto Ferrari ${ }^{14,15}$, Nicola Ferrara ${ }^{16,17,18}$ and Marco Trabucchi ${ }^{3,19,20}$ on behalf of the Italian Study Group on Delirium (ISGoD)

\begin{abstract}
Background: To date, delirium prevalence in adult acute hospital populations has been estimated generally from pooled findings of single-center studies and/or among specific patient populations. Furthermore, the number of participants in these studies has not exceeded a few hundred. To overcome these limitations, we have determined, in a multicenter study, the prevalence of delirium over a single day among a large population of patients admitted to acute and rehabilitation hospital wards in Italy.
\end{abstract}

Methods: This is a point prevalence study (called "Delirium Day") including 1867 older patients (aged 65 years or more) across 108 acute and 12 rehabilitation wards in Italian hospitals. Delirium was assessed on the same day in all patients using the 4AT, a validated and briefly administered tool which does not require training. We also collected data regarding motoric subtypes of delirium, functional and nutritional status, dementia, comorbidity, medications, feeding tubes, peripheral venous and urinary catheters, and physical restraints.

Results: The mean sample age was $82.0 \pm 7.5$ years (58 \% female). Overall, 429 patients (22.9\%) had delirium. Hypoactive was the commonest subtype (132/344 patients, $38.5 \%$ ), followed by mixed, hyperactive, and nonmotoric delirium. The prevalence was highest in Neurology (28.5 \%) and Geriatrics (24.7 \%), lowest in Rehabilitation (14.0\%), and intermediate in Orthopedic (20.6\%) and Internal Medicine wards (21.4\%). In a multivariable logistic regression, age (odds ratio [OR] 1.03, $95 \%$ confidence interval [Cl] 1.01-1.05), Activities of Daily Living dependence (OR 1.19, $95 \% \mathrm{Cl} 1.12-1.27)$, dementia (OR 3.25, 95 \% Cl 2.41-4.38), malnutrition (OR 2.01, $95 \% \mathrm{Cl} 1.29-3.14$ ), and use of antipsychotics (OR 2.03, $95 \% \mathrm{Cl} 1.45-2.82$ ), feeding tubes (OR 2.51, $95 \% \mathrm{Cl} 1.11-5.66$ ), peripheral venous catheters (OR 1.41, $95 \% \mathrm{Cl} 1.06-1.87$ ), urinary catheters (OR 1.73, $95 \% \mathrm{Cl}$ 1.30-2.29), and physical restraints (OR 1.84, $95 \% \mathrm{Cl} 1.40-2.40$ ) were associated with delirium. Admission to Neurology wards was also associated with delirium (OR 2.00, $95 \%$ Cl 1.29-3.14), while admission to other settings was not.

Conclusions: Delirium occurred in more than one out of five patients in acute and rehabilitation hospital wards. Prevalence was highest in Neurology and lowest in Rehabilitation divisions. The "Delirium Day" project might become a useful method to assess delirium across hospital settings and a benchmarking platform for future surveys.

Keywords: Delirium, Prevalence, Hospital, Multicenter, 4AT

\footnotetext{
* Correspondence: giuseppe.bellelli@unimib.it; giuseppebellelli@libero.it

${ }^{1}$ School of Medicine and Surgery, University of Milano-Bicocca, Milano, Italy

${ }^{2}$ Geriatric Unit, San Gerardo University Hospital, Monza, Italy

Full list of author information is available at the end of the article
} 


\section{Background}

Delirium is an acute and fluctuating disorder of attention and cognitive functioning, which is almost always triggered by underlying medical causes and is often accompanied by abnormal arousal and perceptual disturbances [1]. Delirium is associated with many adverse clinical outcomes, including reduction of functional independence, worsening of cognitive performance, and increased mortality [2-4]. Importantly, the mortality risk is associated with delirium per se, independent of the associated medical conditions, and is strongly related to delirium duration [2, 5]. Delirium is also associated with increased costs of care, with more than US\$ 164 billion per year expended in the USA and more than 182 billion Euros per year in Europe [6, 7]. Furthermore, delirium causes higher distress for patients, caregivers, and healthcare professionals $[8,9]$.

However, despite this burden, delirium often goes unrecognized, and its detection is still grossly inadequate in clinical practice [10-12]. Physicians often do not assess a patient's cognition [13, 14], and even if they do, they often fail to recognize the importance of delirium as the interface between mental and physical health $[12,15]$. This is particularly relevant because the inability to detect delirium implies an increased risk of poor outcomes for patients [16]. Conversely, increased knowledge concerning delirium might allow the staff to implement preventive interventions [17] which have been consistently shown to reduce the incidence of delirium in hospitalized patients $[18,19]$ and to ultimately improve their outcomes [20].

A recent review of 35 studies published between 1990 and 2012 reported a prevalence of delirium ranging from $11-42 \%$ in acute hospitals and from 14-18 \% in longterm care and post-acute rehabilitation [4, 21, 22]. However, most of these estimates refer to only a few hundred patients, are based on pooled results from different studies carried out in single wards or hospitals [23-26], and are limited by some methodological heterogeneity. Furthermore, all of them have been performed using diagnostic tools that require preliminary training and/or longstanding experience to be used efficiently [14, 27, 28], with consequent poor transferability of results to clinical practice. To date, only one study assessed delirium across multiple wards of a tertiary hospital within a 24hour period, finding an average prevalence of $20 \%$, but, again, the diagnostic procedures to assess delirium were strongly dependent on the researcher's expertise in delirium [26].

We report here the first nationwide point prevalence study to assess delirium in older (i.e., aged 65 years or more) patients admitted to acute and rehabilitation hospital wards, using a standardized tool that requires neither longstanding experience nor a preliminary training of the assessors [29]. This study was a part of a larger surveillance project, called "Delirium Day," which involved not only acute and rehabilitation hospital wards but also nursing homes, and was widely distributed across Italy.

\section{Methods}

During the 14th National Congress of the Italian Association of Psychogeriatrics (AIP), held in Florence in 2014, an interdisciplinary group of clinicians and researchers belonging to four Italian scientific associations (the AIP, the Italian Society of Gerontology and Geriatrics [SIGG], the Italian Society of Hospital and Community Geriatrics [SIGOT], and the Italian Society of Neurology for Dementia [SINDEM]) discussed the current state of delirium knowledge among healthcare operators in Italy and shared ideas on advancing the best-care practices in this field. The Delirium Day was the result of this collaborative effort. This initiative was conceived both as a method to assess delirium prevalence in various settings of care and as an innovative project to assess delirium to disseminate culture and awareness of the issue among healthcare staff.

\section{Brief description of the Italian hospital care system}

The hospital care in Italy is delivered by more than 600 public and more than 500 private hospitals, especially not-for-profit institutions, which provide both outpatient and inpatient services. The number of hospital beds is approximately 330,000, i.e., less than 3.7 per 1000 inhabitants and there are about 1.78 hospital doctors per 1000 resident population [30]. The facilities participating in this study are all part of the Italian hospital care system.

\section{Study design}

The invitation to participate in this multicenter "point prevalence" study was sent via email to the members of the four scientific associations (globally about 5000), with publication on their websites. Each member was also encouraged to advertise the project and to invite participation by other facilities. Members who voluntarily agreed to participate were invited to send a confirmation email to the following address: deliriumday2015@gmail. com by 15 August 2015. No incentives were offered to participants.

\section{Subjects and study protocol}

September 30, 2015 was the day chosen for the study (index day). All patients admitted to the participating centers from 00:00 to 23:59 of the index day were considered potentially eligible if they were aged 65 years and older, were native Italian speakers, and if they or a proxy provided a written informed consent. Exclusion criteria were coma, aphasia, and end-of-life status, as defined by clinical judgment.

The assessment of the eligible patients was performed by the attending physicians with the following two-step approach. 
Step 1 (mandatory for all patients) (a) Formal cognitive assessment: physicians assessed the eligible patients using the Assessment test for delirium and cognitive impairment (4AT) [29]. The 4AT has recently been validated for the assessment of delirium in patients admitted to acute and rehabilitation hospital wards, showing a sensitivity of $89.7 \%$ and a specificity of $84.1 \%$ for delirium. Its administration is brief (generally less than 2 minutes), and it requires no special training, making delirium assessment feasible by untrained physicians or nurses. A score of 0 suggests neither delirium nor cognitive impairment; scores between 1 and 3 suggest possible general cognitive impairment (that is, corresponding to moderate to severe impairment on standalone dementia screening tools), while a score of 4 or above suggests likely delirium, based on the performance of the 4AT in the original validation study [29]. Thus, in the present study, delirium is defined as a score of 4 or more on the $4 \mathrm{AT}$ instrument. The 4AT form is shown in Additional file 1: Appendix A.

(b)Clinical assessment: For all patients a comprehensive sociodemographic and medical history was collected, including date of hospital admission and functional status prior to admission, using the Activities of Daily Living (ADL) score [31] and the Charlson comorbidity index [32]. Patients were deemed to have dementia if they had documented diagnosis in the medical record and/or were prescribed acetylcholinesterase inhibitors (AChE-I) or memantine prior to admission. Their nutritional status was evaluated referring to the time of assessment and classified according to clinical judgment of the attending physician, as "well nourished," "at risk of malnutrition," or "malnourished." The total number of medications taken by each patient on the index day and the use of specific pharmacological classes (i.e., antihypertensives, antiplatelets, antiarrhythmics, statins/lipid lowering drugs, antidiabetics, antiulcer drugs, antibiotics, benzodiazepines, antipsychotics, antidepressants, antiepileptics, and AChE-I/memantine) were also recorded, together with the use of feeding tubes (i.e., nasogastric tube [NT] or percutaneous endoscopic gastrostomy [PEG] tubes), peripheral venous catheters, urinary catheters, and physical restraints (vests, wrists, inguinal restraints, and bedrails).

Step 2 (for patients scoring $\geq 4 / 12$ on $4 \mathrm{AT}$ ) Motor subtype of delirium: this was measured using the Delirium Motor Subtype Scale (DMSS) [33, 34]. The DMSS is a scale using 11 motor items derived from items used in previous motor subtyping methods but with relative specificity for delirium and demonstrated correlation with objective measures of motor behavior, including electronic motion analysis [35]. It can be rated by any healthcare professional who is familiar with patient behavior, and it can be used to rate the previous 24 hours or more. Each of the 11 symptoms (4 hyperactive and 7 hypoactive features) is rated as present or absent where at least 2 symptoms must be present from either the hyperactive or hypoactive list to meet subtype criteria. Patients meeting both hyperactive and hypoactive criteria were deemed "mixed subtype," while those meeting neither criterion were deemed "no subtype" [34].

\section{Data collection and ethical procedures}

An electronic case report form (e-CRF) was created to collect clinical data, and each center was provided with a username and a password. After accessing the e-CRF, each clinician was asked to indicate the number of eligible patients and the number of those who accepted to participate. Then, an automatic message allowed the clinician to complete the data collection in the e-CRF. It was not possible to submit the data form without the mandatory clinical data. The submission was possible only after clicking on the "Finish survey" button when at least the mandatory assessment was terminated. All transcripts were anonymized, and none of the participants was allowed to see the data of patients from other centers or to identify their names.

The Ethical Committee of the IRCCS Fondazione Santa Lucia, Rome (Prot CE/PROG.500) approved the study protocol. Informed consent was obtained from all participants or from their next of kin when the participants were not capable of giving informed consent themselves because of delirium or severe cognitive impairment. Those who declined to participate in the study were excluded.

\section{Statistical analysis}

The descriptive analysis for quantitative variables was based on calculation of the mean and standard deviation (SD) for parametric distribution or median and interquartile range (IQR) for nonparametric distributions, while qualitative variables were reported as frequencies and percentages. Comparisons between groups were performed using the one-way ANOVA or $t$ test and the Kruskal-Wallis test or Mann-Whitney $U$ test for normally and abnormally distributed data, respectively. Post hoc analyses were performed with the Tukey test or Dunn test when appropriate. The categorical variables were compared between groups using the chi-square test, and Bonferroni corrections were used for pairwise comparisons. We used univariate logistic regression analysis to evaluate the association of variables with delirium. 
Variables found to be statistically significant in the univariate analysis were included in a multiple age- and genderadjusted logistic regression model in order to determine the factors independently associated with delirium. The level of significance was established as $95 \%(p<0.05)$. All analyses were performed using SPSS 22.0 (SPSS Inc., Chicago, IL, USA).

\section{Results}

A total of 161 centers responded to the invitation letter by sending a confirmation email; of these, 37 centers were excluded because they did not collect data on the index day, 2 because they recruited only one patient per center, and 2 because they included patients aged less than 65 years. Overall, 108 acute and 12 rehabilitation hospital wards were involved in the study, of which 60 were located in Northern Italy (30 Geriatrics, 11 Neurology, 9 Rehabilitation, 5 Orthopedics, and 5 Internal Medicine divisions), 40 in Central Italy (24 Geriatrics, 5 Internal Medicine, 5 Neurology, 4 Orthopedics, and 2 Rehabilitation divisions), and 20 in Southern Italy (8 Geriatrics, 7 Internal Medicine, 3 Orthopedics, 1 Neurology, and 1 Rehabilitation division). On the study day, 2221 patients were eligible. Of these, 354 did not consent to participate, leaving a sample of 1867 patients included in the study (Fig. 1). Of these, 1154 patients were from acute Geriatrics, 198 from Internal Medicine, 158 from Neurology, 107 from Orthopedics, and 250 from Rehabilitation wards. The mean age of the whole sample was $82.0 \pm$ 7.5 years, and $58 \%$ were female. Four hundred twenty-nine patients (22.9\%) had delirium, and of those the motoric subtype was characterized in 275 (64.1\%): hypoactive in 106 patients (38.5\%), mixed in 75 (27.3\%), hyperactive in $59(21.5 \%)$, and nonmotoric in 35 (12.7\%), according to DMSS scores.

Table 1 shows the demographic, cognitive, functional, nutritional, and clinical characteristics of subjects with and without delirium. Those with delirium were older and less educated than those without. Moreover, they were also more dependent in functional status, more often malnourished or at risk of malnutrition, and more frequently affected by dementia. There was no difference in regard to medications taken by patients with and without delirium, except for antihypertensives, statins/ lipid lowering drugs, antiulcer drugs, and antibiotics, which were more frequently present in nondelirious patients, and for antipsychotics, antidepressants, and AChE-I/memantine, which were more frequently present in delirious patients. Finally, NTs/PEG tubes, peripheral venous and urinary catheters, and physical restraints were more prevalent among patients with delirium than in those without.

Table 2 shows the characteristics of patients according to the different settings. Those in Geriatrics wards were the oldest and also the most disabled and malnourished. Patients in Neurology wards were the youngest, the least malnourished, and the most frequently affected by dementia; they also were more often treated with benzodiazepines, antipsychotics, antidepressants, antiepileptics, and AChE-I/memantine, and least often with diuretics

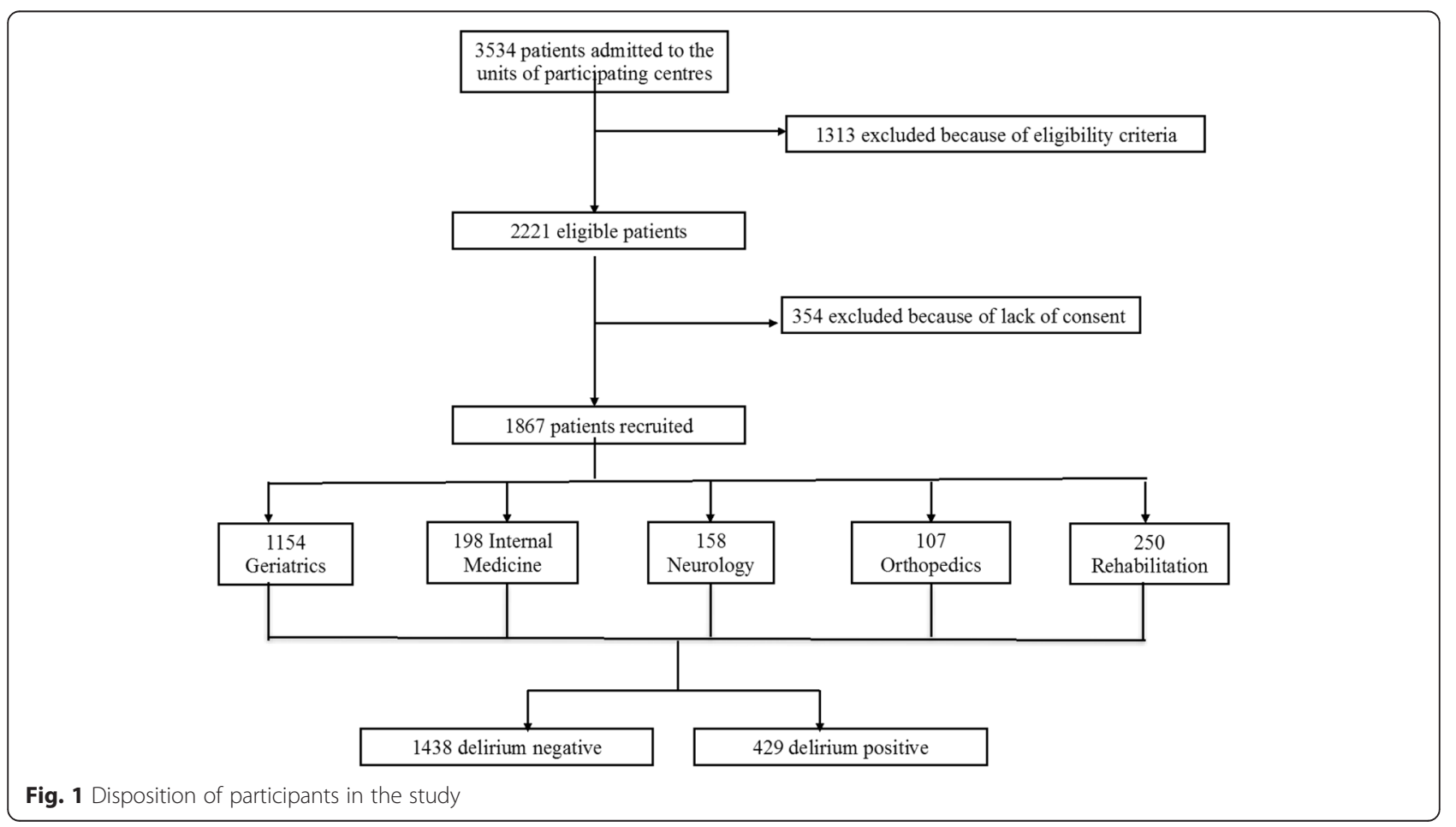


Table 1 Participant characteristics according to diagnosis of delirium

\begin{tabular}{|c|c|c|c|}
\hline & Delirium $(N=429,22.9 \%)$ & No delirium $(N=1438,77.1 \%)$ & $p$ value \\
\hline Age, years & $84.8 \pm 6.7$ & $81.1 \pm 7.6$ & $<.001$ \\
\hline Female gender, $n(\%)$ & $249(58.0)$ & $833(57.9)$ & 1.000 \\
\hline Education, years & $6.2 \pm 3.6$ & $6.8 \pm 3.8$ & .006 \\
\hline ADL before admission, median score (IQR) & $1(0-4)$ & $5(2-6)$ & $<.001$ \\
\hline 0 functions spared & $186(43.4)$ & $155(10.8)$ & \\
\hline 1 function spared & $66(15.4)$ & $174(12.1)$ & $<.001$ \\
\hline 2 to 5 functions spared & $118(27.5)$ & $471(33.8)$ & \\
\hline 6 functions spared & $59(13.8)$ & $638(44.4)$ & \\
\hline \multicolumn{4}{|l|}{ Nutritional status, $n(\%)$} \\
\hline Well nourished & $156(36.4)$ & $949(66.0)$ & $<.001$ \\
\hline At risk of malnutrition & $215(50.1)$ & $414(28.8)$ & \\
\hline Malnourished & $58(13.5)$ & $75(5.2)$ & \\
\hline Charlson index (excluding dementia), median score (IQR) & $2(1-4)$ & $2(1-4)$ & .87 \\
\hline Dementia, $n(\%)$ & $227(52.9)$ & $222(15.4)$ & $<.001$ \\
\hline No. of drugs, on admission, median score (IQR) & $5(4--7)$ & $5(3-7)$ & .56 \\
\hline Diuretics, $n(\%)$ & $202(47.1)$ & $727(50.6)$ & .22 \\
\hline Antihypertensive drugs, $n$ (\%) & $241(56.2)$ & $939(65.3)$ & .001 \\
\hline Antiplatelet drugs, $n$ (\%) & $174(49.6)$ & $612(42.6)$ & .47 \\
\hline Antiarrhythmic drugs, $n(\%)$ & $39(9.1)$ & $173(12.0)$ & .10 \\
\hline Statins/lipid lowering drugs, $n(\%)$ & $45(10.5)$ & $297(20.7)$ & $<.001$ \\
\hline Antidiabetics (including insulin), $n$ (\%) & $72(16.8)$ & $284(19.7)$ & .18 \\
\hline Antiulcer drugs, $n(\%)$ & $270(62.9)$ & $980(68.2)$ & .04 \\
\hline Antibiotics, $n(\%)$ & $186(43.4)$ & $433(30.1)$ & $<.001$ \\
\hline Benzodiazepines, $n$ (\%) & $93(21.7)$ & $360(25.0)$ & .16 \\
\hline Antipsychotics, $n$ (\%) & $107(28.3)$ & $119(9.1)$ & $<.001$ \\
\hline Antidepressants, n (\%) & $112(26.1)$ & $278(19.3)$ & .003 \\
\hline Antiepileptics, n (\%) & $32(7.5)$ & $93(6.5)$ & .51 \\
\hline AChE-I/memantine, $n(\%)$ & $15(3.5)$ & $24(1.7)$ & .03 \\
\hline Feeding tubes (NT or PEG), $n$ (\%) & $20(4.7)$ & $20(1.4)$ & $<.001$ \\
\hline Venous catheter, $n(\%)$ & $244(56.9)$ & $694(42.0)$ & $<.001$ \\
\hline Urinary catheter, $n(\%)$ & $199(46.4)$ & $340(23.6)$ & $<.001$ \\
\hline Physical restraints, $n$ (\%) & $268(62.5)$ & $427(29.7)$ & $<.001$ \\
\hline
\end{tabular}

Data are expressed as mean + SD unless otherwise specified; IQR interquartile range, $p$ value: significance at one-way ANOVA or $t$ test and at Kruskal-Wallis test or Mann-Whitney $U$ test for normally and abnormally distributed data, respectively

$A D L$ Activities of Daily Living score, AChE-I acetylcholinesterase inhibitors, NT nasogastric tube, PEG percutaneous endoscopic gastrostomy

and antiplatelet medications. Patients in Orthopedic wards had the highest prevalence of peripheral venous and urinary catheter use, those in Internal Medicine wards had the highest antibiotic use, and those in Rehabilitation wards were the most educated and had the lowest frequency of peripheral venous and urinary catheters.

The prevalence of delirium was highest in the Neurology $(28.5 \%$; 45/158) and Geriatrics wards (24.7\%; $285 / 1154)$, lowest in Rehabilitation (14.0\%; 35/250), and intermediate in Orthopedic $(20.6 \% ; 22 / 107)$ and Internal Medicine wards (21.2\%; 42/198) (Fig. 2). The overall delirium prevalence in acute hospital wards, excluding Rehabilitation, was $24.4 \%$ (394/1617).

In the multivariable logistic regression analysis (Table 3) the following variables were significantly associated with delirium: age (OR 1.03, 95 \% CI 1.01-1.05), ADL dependence (OR 1.19, $95 \%$ CI 1.12-1.27), dementia (OR 3.25, 95 \% CI 2.41-4.38), malnutrition (OR 2.01, 95 \% CI 1.293.14), antipsychotics (OR 2.03, 95 \% CI 1.45-2.82), feeding tubes (OR 2.51, $95 \%$ CI 1.11-5.66), peripheral venous catheters (OR 1.41, $95 \%$ CI 1.06-1.87), urinary catheters (OR 1.73, 95 \% CI 1.30-2.29), and physical restraints (OR 
Table 2 Participant characteristics according to settings of admission

\begin{tabular}{|c|c|c|c|c|c|c|}
\hline & $\begin{array}{l}\text { Rehabilitation } \\
(N=250)\end{array}$ & $\begin{array}{l}\text { Geriatrics } \\
(N=1154)\end{array}$ & $\begin{array}{l}\text { Orthopedics } \\
(N=107)\end{array}$ & $\begin{array}{l}\text { Neurology } \\
(N=158)\end{array}$ & $\begin{array}{l}\text { Int. Medicine } \\
(N=198)\end{array}$ & $p$ value \\
\hline Age, years & $80.4 \pm 7.7^{b, d}$ & $83.2 \pm 7.1^{\mathrm{a}, c, \mathrm{~d}, \mathrm{e}}$ & $80.8 \pm 8.4^{b, d}$ & $77.7 \pm 7.2^{a, b, c, e}$ & $80.7 \pm 7.7^{b, d}$ & $<0.001$ \\
\hline Female gender, $n(\%)$ & $153(61.2)$ & $679(58.8)$ & $72(67.3)^{\mathrm{e}}$ & $81(51.3)$ & $97(49.0)^{c}$ & 0.005 \\
\hline Education, years & $7.3 \pm 3.7^{\mathrm{b}, \mathrm{e}}$ & $6.5 \pm 3.8^{a}$ & $7.2 \pm 4.5$ & $7.0 \pm 3.7$ & $6.9 \pm 3.4^{a}$ & 0.004 \\
\hline ADL before admission, mean score & $5(1-6)^{b}$ & $4(1-6)^{a, c, d, e}$ & $5(3-6)^{b}$ & $5(2-6)^{b}$ & $5(2-6)^{b}$ & $<0.001$ \\
\hline 0 functions spared, $n$ (\%) & $32(12.8)$ & $255(22.1)$ & $8(7.5)$ & $22(13.9)$ & $24(12.1)$ & \\
\hline 1 function spared, $n(\%)$ & $34(13.6)$ & $156(13.5)$ & $9(8.4)$ & $16(10.1)$ & $25(12.6)$ & $<0.001$ \\
\hline 2 to 5 functions spared, $n$ (\%) & $92(36.8)$ & $349(30.2)$ & $41(38.3)$ & $45(28.5)$ & $62(31.3)$ & \\
\hline 6 functions spared, $n$ (\%) & $92(36.8)$ & $394(34.1)$ & $49(45.8)$ & $75(47.5)$ & $87(43.9)$ & \\
\hline \multicolumn{7}{|l|}{ Nutritional status, $n(\%)$} \\
\hline Well nourished & $171(68.4)^{b, d}$ & $601(52.1)^{\mathrm{a}, \mathrm{d}, \mathrm{e}}$ & $61(57.0)^{d}$ & $130(82.3)^{a, b, c}$ & $142(71.7)^{b}$ & $<0.001$ \\
\hline At risk of malnutrition & $60(24.0)^{\mathrm{a}}$ & $457(39.6)^{\mathrm{b}, \mathrm{d}, \mathrm{e}}$ & $37(34.6)^{d}$ & $27(17.1)^{b, c}$ & $48(24.2)^{b}$ & \\
\hline Malnourished & $19(7.6)^{d}$ & $96(8.3)^{d}$ & $9(8.4)^{d}$ & $1(0.6)^{a, b, c}$ & $8(4.0)$ & \\
\hline Charlson index (excluding dementia) & $1(0-3)^{b, e}$ & $3(1-5)^{a, c, d}$ & $1(0-3)$ b,e & $2(1-3)^{b, e}$ & $3(1-4)^{a, c, d}$ & $<0.001$ \\
\hline Dementia, $n(\%)$ & $50(20.0)^{d}$ & $304(26.3)^{d}$ & $18(16.8)$ & $60(38.0)^{a, b, e}$ & $33(16.7)^{d}$ & $<0.001$ \\
\hline No. drugs, on admission & $5(3-6)^{e}$ & $5(4-7)^{c}$ & $4(3-6)^{b}$ & $5(3-6)^{e}$ & $6(4-7)^{\mathrm{a}, \mathrm{d}}$ & $<0.001$ \\
\hline Diuretics, $n$ (\%) & $122(48.8)^{d}$ & $624(54.1)^{c, e}$ & $36(33.6)^{b}$ & $80(31.6)^{a, b, e}$ & $97(49.0)^{d}$ & $<0.001$ \\
\hline Antihypertensive, $n$ (\%) & $157(62.8)$ & $723(62.7)$ & $62(57.9)$ & $99(62.7)$ & $139(70.2)$ & 0.228 \\
\hline Antiplatelet drugs, $n$ (\%) & $93(37.2)^{d}$ & $473(41.0)^{d}$ & $37(34.6)^{d}$ & $80(31.6)^{a, b, c, e}$ & $97(49.0)^{d}$ & $<0.001$ \\
\hline Antiarrhythmic drugs, $n$ (\%) & $27(10.8)$ & $139(12.0)$ & $7(6.5)$ & $11(7.0)$ & $28(14.1)$ & 0.106 \\
\hline Statins/lipid lowering drugs, n (\%) & $56(22.4)$ & $183(15.9)^{d}$ & $15(14.0)$ & $41(25.9)^{b}$ & $47(23.7)$ & 0.001 \\
\hline Antidiabetics (including insulin), $n(\%)$ & $34(13.6)$ & $227(19.7)$ & $18(16.8)$ & $30(19.0)$ & $47(23.7)$ & 0.082 \\
\hline Antiulcer drugs, $n(\%)$ & $166(66.4)$ & $783(67.9)^{\mathrm{d}}$ & $74(69.2)$ & $87(55.1)^{\mathrm{b}, \mathrm{e}}$ & $140(70.7)^{d}$ & 0.017 \\
\hline Antibiotics, $n(\%)$ & $26(10.4)^{b, c, e}$ & $448(38.8)^{a, d}$ & $38(35.5)^{\mathrm{a}, \mathrm{d}}$ & $22(13.9)^{b, c, e}$ & $85(42.9)^{a, d}$ & $<0.001$ \\
\hline Benzodiazepines, $n$ (\%) & 74 (29.6) & $259(22.4)$ & $25(23.4)$ & $51(32.3)$ & $44(22.2)$ & 0.018 \\
\hline Antipsychotics, $n(\%)$ & $29(11.6)^{d}$ & $163(14.1)^{d}$ & $10(9.3)^{d}$ & $42(26.6)^{a, b, c, e}$ & $19(9.6)^{d}$ & $<0.001$ \\
\hline Antidepressants, $n(\%)$ & $60(24.0)$ & $226(19.6)^{d}$ & $22(20.6)$ & $50(31.6)^{\mathrm{b}, \mathrm{e}}$ & $32(12.6)^{d}$ & 0.003 \\
\hline Antiepileptics, n (\%) & $24(9.6)^{c, d}$ & $61(5.3)^{d}$ & $0^{\mathrm{a}, \mathrm{d}}$ & $34(21.5)^{a, b, c, e}$ & $6(3.0)^{d}$ & $<0.001$ \\
\hline AChE-I/memantine, $n(\%)$ & $4(1.6)$ & $22(1.9)^{d}$ & $1(0.9)$ & $10(6.3)^{\mathrm{b}}$ & $1(1.0)$ & 0.003 \\
\hline Feeding tubes (NT or PEG), $n$ (\%) & $3(1.2)$ & $23(2.0)$ & $4(3.7)$ & $5(3.2)$ & $5(2.5)$ & 0.492 \\
\hline Venous catheter, n (\%) & $26(10.4)^{b, c, d, e}$ & $577(50.0)^{\mathrm{a}, \mathrm{c}, \mathrm{d}, \mathrm{e}}$ & $75(70.1)^{a, b, d}$ & $34(21.5)^{a, b, c, e}$ & $136(68.7)^{a, b, d}$ & $<0.001$ \\
\hline Urinary catheter, $n(\%)$ & $28(11.2)^{b, c, d, e}$ & $364(31.5)^{a, c}$ & $66(61.7)^{a, b, d, e}$ & $35(22.2)^{\mathrm{a}, \mathrm{c}}$ & $46(23.2)^{a, c}$ & $<0.001$ \\
\hline Physical restraints, $n$ (\%) & $68(27.2)^{b}$ & $465(40.3)^{a}$ & $44(41.1)$ & $52(32.9)$ & $62(31.1)$ & $<0.001$ \\
\hline
\end{tabular}

Data are expressed as mean +SD unless otherwise specified; IQR interquartile range, ADL Activities of Daily Living score, AChE-I acetylcholinesterase inhibitors, NT nasogastric tube, $P E G$ percutaneous endoscopic gastrostomy

$p$ denotes significance on ANOVA for continuous or chi-square for categorical variables. Where significant group effects were detected, either Turkey or Dunn or Bonferroni tests indicated significant post hoc differences between individual groups, as follows:

${ }^{\mathrm{a} S i g n i f i c a n t}$ difference with Rehabilitation group

${ }^{\mathrm{b}}$ Significant difference with Geriatrics group

'Significant difference with Orthopedics group

${ }^{\mathrm{d}}$ Significant difference with Neurology group

ésignificant difference with Internal Medicine group

1.84, $95 \%$ CI 1.40-2.40). Moreover, taking admission to Rehabilitation as a reference category, being admitted to Neurology wards remained independently associated with delirium occurrence (OR 2.00, 95 \% CI 1.10-3.64), while admission to other settings did not.

\section{Discussion}

To our knowledge, this is the first nationwide multicenter study to assess the prevalence of delirium in elderly patients across acute and rehabilitation hospital wards over a single day. Delirium prevalence was $22.9 \%$ in the 


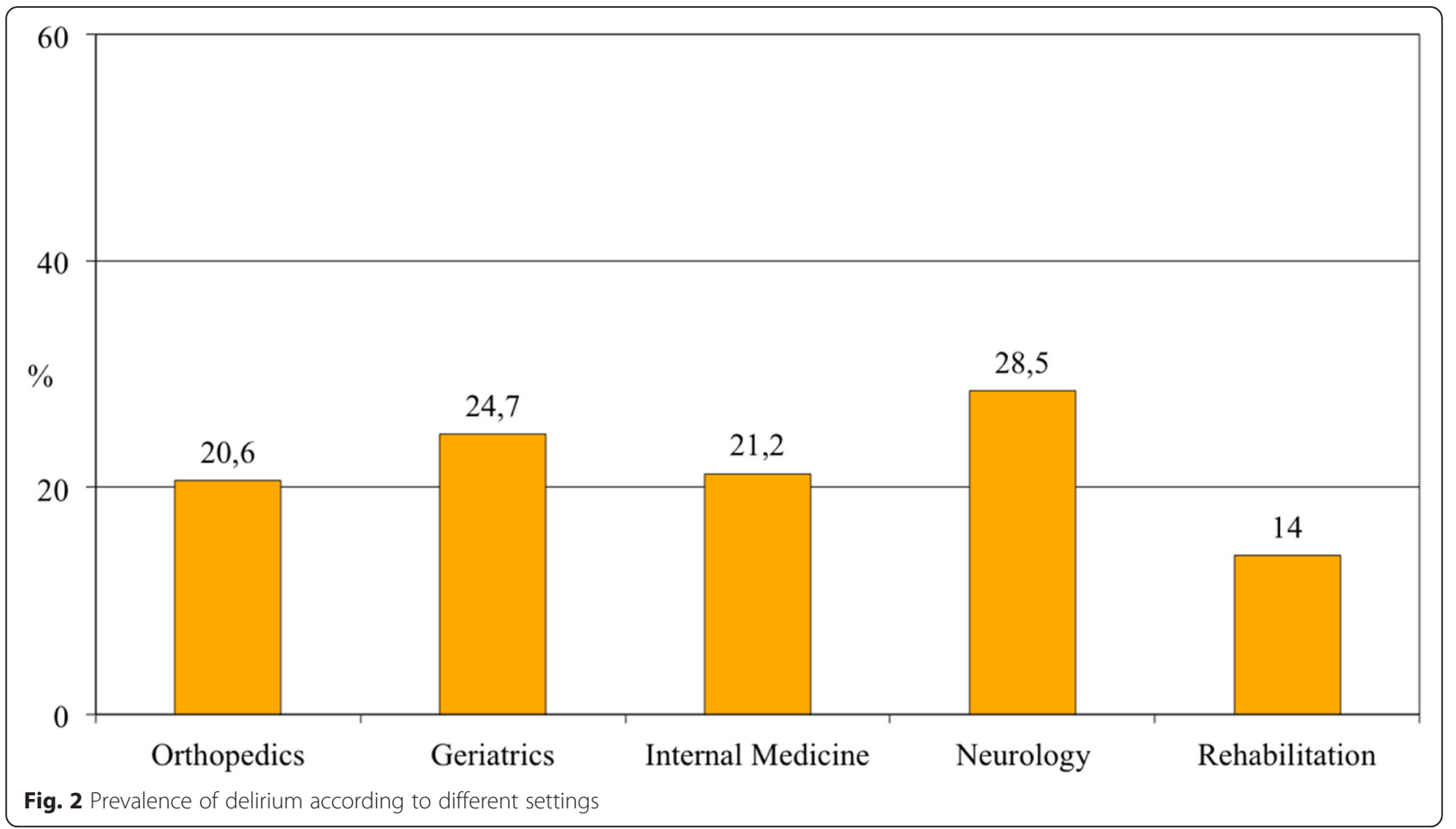

entire sample. The most common subtype was hypoactive, followed by mixed and then hyperactive and finally by nonmotoric. Prevalence was highest in Neurology and Geriatrics and lowest in Rehabilitation hospital wards. Delirium occurrence was independently associated with the more elderly, ADL dependence, dementia, malnutrition, and use of antipsychotics, feeding tubes, peripheral venous and urinary catheters, and physical restraints. Moreover, taking admission to Rehabilitation as a reference category, being admitted to Neurology wards was also associated with delirium occurrence, while admission to other settings was not.

Although our findings are consistent with those of the existing literature $[4,36]$, previous studies have assessed the prevalence of delirium in a single hospital [23-25, 37-39] or at no more than three hospitals [40, 41] and/ or involved only one type of specialist ward per study (i.e., only Internal Medicine, Geriatrics, or Orthopedic units). Other studies conducted in Neurology and Orthopedic wards have mainly focused on the incidence of delirium rather than on its prevalence [4, 42-45], which explains the lack of such data in these settings. The few studies in Rehabilitation settings found a delirium prevalence ranging from $13-18 \%[21,22]$, but, again, these data referred to a single hospital or were combined. The results of the only point prevalence delirium study [26] available to date were similar to those of our study. Ryan and colleagues included 280 patients from different wards of a medium-size tertiary hospital in Ireland. Using a set of well-validated tools, a trained team of delirium experts found in this population a delirium prevalence of $19.6 \%$ with the Diagnostic and Statistical Manual of Mental Disorders (DSM)-IV criteria, $17.6 \%$ with the Confusion Assessment Method (CAM), and $20.7 \%$ with the Delirium Rating Scale-Revised-98 (DRS-R98) [26]. Several hospital wards were screened for delirium prevalence, including Geriatrics and Internal Medicine, Oncology and Radiotherapy, General Surgery, Neurosurgery, and Orthopedics [26]. However, data from some wards were very limited in number, preventing the researchers from establishing a setting-specific prevalence of delirium.

In the present study, we achieved a large participation from Geriatric, Internal Medicine, Neurology, and Orthopedic wards distributed in 18 out of 20 Italian regions, allowing us to obtain a representative picture of the impact of delirium across Italian hospitals. These data confirm that delirium is not exclusive to specific healthcare settings, but is common in all studied hospital wards, in spite of the clear differences observed among patients in the different settings. The highest prevalence of delirium observed in Geriatric and Neurology wards might be explained by the highest prevalence of risk factors for delirium: old age, disability, and malnutrition, which were most frequent in Geriatrics, while both dementia and use of psychotropic medications were highest in Neurology wards. The independent association between the admission to Neurology wards and delirium might have several explanations. Consistent with patients' features, the unmeasured confounding of behavioral and psychological symptoms associated with dementia might be more frequent in this setting. The 
Table 3 Univariate and multivariate analyses of factors associated with delirium

\begin{tabular}{|c|c|c|c|c|c|c|c|}
\hline & & Univà & nalysis & & Multi & analysis & \\
\hline & Number & OR & $95 \% \mathrm{Cl}$ & $p$ value & $\mathrm{OR}$ & $95 \% \mathrm{Cl}$ & $p$ value \\
\hline Age & & 1.07 & $1.05-1.09$ & $<.001$ & 1.03 & $1.01-1.05$ & .006 \\
\hline Female sex & $180 / 785$ & .99 & $.80-1.24$ & .97 & - & - & - \\
\hline Education, years & & .96 & $.93-.99$ & .008 & 1.00 & $.97-1.04$ & .77 \\
\hline Rehabilitation wards & $35 / 250$ & Ref & & & Ref & & \\
\hline Geriatrics wards & $285 / 1154$ & 2.02 & $1.38-2.95$ & $<.001$ & 1.15 & $.72-1.83$ & .56 \\
\hline Orthopedic surgery wards & $22 / 107$ & 1.59 & $.88-2.87$ & 0.12 & - & - & - \\
\hline Neurology wards & $45 / 158$ & 2.45 & $1.49-4.02$ & $<.001$ & 2.00 & $1.10-3.64$ & .02 \\
\hline Internal Medicine wards & $42 / 198$ & 1.65 & $1.01-2.71$ & .05 & 1.40 & $.77-2.57$ & .27 \\
\hline ADL (functions lost) & & 1.45 & $1.38-1.53$ & $<.001$ & 1.19 & $1.12-1.27$ & $<.001$ \\
\hline Dementia (yes/no) & $243 / 465$ & 7.16 & $5.64-9.08$ & $<.001$ & 3.25 & $2.41-4.38$ & $<.001$ \\
\hline Malnutrition (yes/no) & $58 / 133$ & 2.84 & $1.98-4.08$ & $<.001$ & 2.01 & $1.29-3.14$ & .002 \\
\hline Antihypertensives (yes/no) & $241 / 1180$ & .68 & $.55-.85$ & .001 & .84 & $.64-1.09$ & .18 \\
\hline Statins/lipid lowering (yes/no) & $45 / 342$ & .45 & $0.32-0.63$ & $<.001$ & .79 & $.53-1.17$ & .23 \\
\hline Antibiotics (yes/no) & $186 / 619$ & 1.78 & $1.42-2.22$ & $<.001$ & 1.24 & $0.93-1.64$ & .14 \\
\hline Antipsychotics (yes/no) & $132 / 263$ & 4.43 & $3.38-5.82$ & $<.001$ & 2.03 & $1.45-2.82$ & $<.001$ \\
\hline Antidepressants (yes/no) & $112 / 390$ & 1.47 & $1.15-1.90$ & .003 & 1.03 & $.76-1.41$ & .83 \\
\hline Antiulcer drugs (yes/no) & $270 / 1250$ & .79 & $.63-.99$ & .04 & .86 & $.65-1.13$ & .27 \\
\hline AChE-I/memantine (yes/no) & $15 / 39$ & 2.14 & $1.11-4.11$ & .03 & .91 & $.42-1.97$ & .81 \\
\hline Feeding tubes (NT or PEG) (yes/no) & $20 / 40$ & 3.47 & $1.85-6.51$ & $<.001$ & 2.51 & $1.11-5.66$ & .03 \\
\hline Peripheral venous catheters (yes/no) & $244 / 848$ & 1.82 & $1.47-2.27$ & $<.001$ & 1.41 & $1.06-1.87$ & .02 \\
\hline Urinary catheters (yes/no) & 199/539 & 2.79 & $2.23-3.50$ & $<.001$ & 1.73 & $1.30-2.29$ & $<.001$ \\
\hline Physical restraints (yes/no) & $268 / 695$ & 3.94 & $3.15-4.94$ & $<.001$ & 1.84 & $1.40-2.40$ & $<.001$ \\
\hline
\end{tabular}

OR odds ratio, $95 \% \mathrm{Cl} 95 \%$ confidence interval, Ref reference value for the hospital wards, ADL Activities of Daily Living score, AChE-I acetylcholinesterase inhibitors, NT nasogastric tube, PEG percutaneous endoscopic gastrostomy

presence of such symptoms might both increase the risk of delirium [45] and be misdiagnosed as delirium itself, especially for the features "alertness" and "fluctuating course" of the 4AT. Alternatively, a selection bias might be present, with delirium cases being referred more often to Neurology from emergency departments. Overall, these findings strongly suggest that delirium in acute Neurology wards should be regarded as a potential target of interest for future studies.

The other variables associated with delirium in the present study have all been recognized as predictors in previous prospective researches [4]. In particular, according to Inouye's model [46], we found that both predisposing (i.e., age, disability, dementia, and malnutrition) and precipitating factors (i.e., use of antipsychotics, feeding tubes, peripheral venous and urinary catheters, and physical restraints) were associated with delirium occurrence in the whole population, thus confirming the multifactorial nature of this syndrome.

The frequency of the delirium motoric subtypes in our study is in keeping with previous ones carried out on smaller populations $[47,48]$. Because the most prevalent delirium subtype was the hypoactive one, which is at highest risk of underdetection [28], we also claim the importance of an active case finding in clinical practice using standardized tools in order to avoid misdetection. Conversely, the hyperactive form of delirium, which is the most readily recognized, was also found to be the least prevalent.

The present study has several implications for clinicians and policymakers. Indeed, because delirium prevalence is in keeping with previous studies that used more accurate diagnostic methods $[4,26]$, our study indirectly shows that multicenter studies in this field are both feasible and reliable, even with physicians untrained in the diagnosis of delirium. We also pose that the use of 4AT in similar initiatives might be an aid in the comparison of delirium prevalence among different healthcare settings, increasing delirium awareness among healthcare providers. Finally, although a causal relationship could not be established in our study due to its cross-sectional design, the high prevalence of modifiable factors associated with delirium (malnutrition, antipsychotic use, feeding tubes, peripheral venous and urinary catheters, and physical restraints) 
suggests that a relationship may exist between delirium and these factors. Hence, future studies are needed to investigate potential relationships between these care practices and delirium.

Strengths of the present study include the large sample and the inclusion of more than 100 healthcare facilities from different settings. A second strength is the adoption of a common assessment protocol based on the detection of delirium with the 4AT, a simple tool that requires neither preliminary training nor longstanding experience to be administered. In fact, previous studies have generally used diagnostic instruments and/or criteria that are timeconsuming or difficult to implement in clinical practice $[27,49]$, which may represent potential barriers to improving delirium detection in clinical practice $[13,50]$.

Some limitations of this study should be acknowledged. First, the participation in our study was on a volunteer basis, and therefore ours is a convenience sample. Second, it might be possible that centers participating in the present survey self-selected for a moderate-to-high attention to the issue and were therefore not fully representative of acute hospitals and rehabilitation settings in Italy. Third, we did not collect data regarding the main reasons of hospital admission, thus preventing us from assessing the role of precipitating factors of delirium, such as stroke and infections. Fourth, it might be possible that the diagnosis of dementia may have been underreported in medical records and that only a percentage of people with dementia would have been prescribed AChE-Is or memantine, leading to dementia being underreported in our study, and consequently, some cases of dementia may have been misclassified as delirium. Fifth, delirium in this study was defined with a brief assessment tool, the 4AT, rather than with a comprehensive reference standard. This was necessary for reasons of practicality; nevertheless, the tool has good sensitivity and specificity for delirium in the original study and in other published studies [51, 52]. Lastly, we cannot exclude the possibility that the 4AT may have at least partially overestimated the prevalence of delirium in subjects with pre-existing dementia. Indeed, in the validation study, the 4AT was shown to have good sensitivity but lower specificity in these patients [29].

\section{Conclusions}

In conclusion, this is so far the largest point prevalence study of delirium on a national level, showing a prevalence of more than one out of five patients across different hospital wards. A reliable and widespread assessment of delirium may be obtained through the use of a simple and validated tool, thus allowing large-scale detection of this too often unrecognized condition. We suggest that "Delirium Day" might be performed in different countries and repeated over time in Italy, both as a supportive educational strategy to improve delirium awareness and as a potential benchmarking platform to assess the quality of assistance provided in different facilities.

\section{Additional file}

Additional file 1: The $4 A T$ test. (DOCX $51 \mathrm{~kb})$

\section{Abbreviations}

AChE-I, acetylcholinesterase inhibitor; ADL, Activities of Daily Living; AIP Italian Association of Psychogeriatrics; CAM, Confusion Assessment Method; DMSS, Delirium Motor Subtype Scale; DRS-R98, Delirium Rating Scale-Revised-98; DSM, Diagnostic and Statistical Manual of Mental Disorders; e-CRF, electronic case report form; IQR, interquartile range; NT, nasogastric tube; PEG, percutaneous endoscopic gastrostomy; SD, standard deviation; SIGG, Italian Society of Gerontology and Geriatrics; SIGOT, Italian Society of Hospital and Community Geriatrics; SINDEM Italian Society of Neurology for Dementia; SPSS, Statistical Package for the Social Sciences

\section{Acknowledgements}

The authors gratefully acknowledge the contributions of the patients, family members, nurses, physicians, staff members, and members of the Executive Steering Committee. We are indebted to Professor Zambon (Department of Statistics and Quantitative Methods, Unit of Biostatistics, Epidemiology and Public Health, University of Milano-Bicocca) for her support to Dr. Mazzone in the statistical analyses and to Mrs. Margareth Warren for the revision of the English language.

The members of the Italian Study Group on Delirium (ISGOD) are: Stefano Boffelli, Fabio Di Stefano, Francesco De Filippi, Fabio Guerini, Erik Bertoletti, Albert March, Alessandro Margiotta, Patrizia Mecocci, Desireè Addesi, Fausto Fantò, Gianluca Isaia, Babette Dijik, Paola Porrino, Antonino Maria Cotroneo, Giovanni Galli, Amalia Cecilia Bruni, Bruno Bernardini, Carla Corsini, Annachiara Cagnin, Amedeo Zurlo, Giuseppe Barbagallo, Maria Lia Lunardelli, Emilio Martini, Giuseppe Battaglia, Raffaele Latella, Donatella Petritola, Elena Sinforiani, Alberto Cester, Marino Formilan, Pasqualina Carbone,

Ildebrando Appollonio, Diletta Cereda, Lucio Tremolizzo; Edo Bottacchi, Lucio Lucchetti, Claudio Mariani, Piero Rapazzini, Giuseppe Romanelli, Alessandra Marengoni, Giovanni Zuliani, Lara Bianchi, Teresa Suardi, Ettore Muti, Renato Bottura, Giovanni Sgrò, Antonella Mandas, Luca Serchisu, Patrizia Crippa, Claudio Ivaldi, Andrea Ungar, Daniele Villani, Clara Raimondi, Chiara Mussi, Giancarlo Isaia, Giuseppe Provenzano, Daniela Mari, Patrizio Odetti, Fiammetta Monacelli, Raffaele Antonelli Incalzi, Alice Pluderi, Claudio Bellamoli, Luciano Terranova, Elio Scarpini, Ferdinando D'Amico, Maria Chiara Cavallini, Gianbattista Guerrini, Anna Maria Scotuzzi, Antonino Chiarello, Alberto Pilotto, Sara Tognini, Giuseppina Dell'Aquila, Gabriele Toigo, Giuliano Ceschia, Maristella Piccinini, Andrea Fabbo, Marco Zoli, Paola Forti, Christian Wenter, Giorgio Basile, Anna Lasagni, Alessandro Padovani, Luca Rozzini, Maria Cottino, Silvia Vitali, Gabriele Tripi, Stefano Avanzi, Giorgio Annoni, Giovanni Ruotolo, Federica Boschi, Paolo Bonino, Niccolò Marchionni, Maria C. Cavallini, Sara Fascendini, Gabriele Noro, Renato Turco, Maria C. Ubezio, Carlo Serrati, Maria Infante, Simona Gentile, Luigi M. Pernigotti, Carlo A. Biagini, Enzo Canonico, Pietro Bonati, Pietro Gareri, Paolo Caffarra, Arcangelo Ceretti, Rosanna Castiglia, Carlo Gabelli, Mario Lo Storto, Paolo Putzu, Giuseppe Bellelli, Alessandro Morandi, Simona Di Santo, Andrea Mazzone, Renzo Rozzini, Ermellina Zanetti, Angelo Bianchetti, Mario Bo, Enrico Mossello, Antonio Cherubini, Nicola Ferrara, Alberto Ferrari, Massimo Musicco, Marco Trabucchi.

We also acknowledge the following investigators for their collaboration in data collection:

Alba Malara, Fausto Spadea, Serena Di Cello, Francesco Ceravolo, Francesco Fabiano, Vincenzo Rispoli, Giuseppe Chiaradia, Amedeo Gabriele, Vincenzo Settembrini, Domenico Capomolla, Antonella Citrino, Antonietta Scriva, Irene Bruno, Roberto Secchi, Eugenio De Martino, Roberto Muccinelli, Gerardo Lupi, Patrizio Paonessa, Andrea Fabbri, Sofia Castellari, Andrea Po, Guido Gaggioli, Massimo Varesi, Paolo Moneti, Sebastiano Capurso, Vincenzo Latini, Stefano Ghidotti, Francesco Riccardelli, Maurizio Macchi, Stefano Boffelli, Angela Cassinadri, Gabriele Tonini, Laura Andreani, Mirco Coralli, Antonio Balotta, Roberto Cancelliere, Mara Strazzacapa, Pierangela Cavallino, Stefano 
Fabio, Francesco De Filippi, Chiara Giudice, Patrizia Floris, Cosimo Dentizzi, Katia D'Elia, Margherita Azzini, Marco Cazzadori, Claudia Benati, Chiara Tobaldini, Angela Antonioli, Fabio Guerini, Paolo Mombelloni, Fulvio Fontanini, Martina Oliverio, Luciano Del Grosso, Cristina Giavedoni, Giuliano Bidoli, Bruno Mazzei, Andrea Corsonello, Sergio Fusco, Silvio Vena, Tommaso De Vuono, Giorgio Maiuri, Eugenio Castegnaro, Salvatore De Rosa, Rossella Bazzano Sechi, Enrico Benvenuti, llaria Del Lungo, Sante Giardini, Chiara Giulietti, Erik Bertoletti, Ferdinando D'Amico, Francesco Caronzolo, Alessandro Grippa, Giuseppina Lombardo, Tiziana Pipicella, Albert March, Maria Teresa Nitti, Alessandro Felici, Silvia Pavan, Fabrizio Piazzani, Alessandra Lunelli, Sergio Dimori, Angelo Magnani, Alessandro Margiotta, Tiziano Soglia, Demetrio Postacchini, Roberto Brunelli, Silvia Santini, Monia Francavilla, llenia Macchiati, Francesca Sorvillo, Cinzia Giuli, Patrizia Mecocci, Francesco Perticone, Desireè Addesi, Paola Cerra Rosa, Giuseppe Bencardino, Tania Falbo, Nadia Grillo, Fausto Fantò, Gianluca Isaia, Stella Pezzilli, Daniele Bergamo, Elisabetta Furno, Sokol Rrodhe, Simonetta Lucarini, Babette Dijik, Francesca Dall'Acqua, Francesco Cappelletto, Donatella Calvani, Dimitri Becheri, Lucia Gambardella, Carlo Valente, Paola Porrino, Giacomo Ceci, Evaristo Ettorre, Sara Tironi, Maria Grazia Grassi, Elio Troisi, Anna Gabutto, Nino Baglietto, Loredana Quazzo, Annalisa Rosatello, Domenico Suraci, Benedetta Tagliabue, Chiara Perrone, Lucia Ferrara, Alberto Castagna, Maria Luisa Tremolada, Simonetta Piano, Gaetano Serviddio, Aurelio Lo Buglio, Tiziana Gurrera, Valeria Merlo, Carla Rovai, Antonino Maria Cotroneo, Rosaria Carlucci, Anna Abbaldo, Fabio Monzani, Ahmad Amedeo Qasem, Giacomo Bini, Silvia Tafuto, Giovanni Galli, Amalia Cecilia Bruni, Giovanna Mancuso, Bruno Bernardini, Carla Corsini, Annachiara Cagnin, Federica Fragiacomo, Sara Pompanin, Amedeo Zurlo, Gianluca Guerra, Marco Pala, Luca Menozzi, Chiara Delli Gatti, Stefania Magon, Vincenzo Di Francesco, Silvia Faccioli, Luca Pellizzari, Giuseppe Barbagallo, Maria Lia Lunardelli, Emilio Martini, Maria Macchiarulo, Maria Corneli, Monica Bacci, Giuseppe Battaglia, Mario Lo Storto, Chiara Seresin, Matteo Simonato, Michele Loreggian, Fausta Cestonaro, Mario Durando, Raffaele Latella, Marta Mazzoleni, Giuseppe Russo, Martino Ponte, Alessandro Valchera, Giuseppe Salustri, Donatella Petritola, Alfredo Costa, Elena Sinforiani, Matteo Ramusino Cotta, Simonetta Piano, Renato Nicola Pizio, Germana Perego, Alberto Cester, Marino Formilan, Pasqualina Carbone, Ildebrando Appollonio, Diletta Cereda, Lucio Tremolizzo; Edo Bottacchi, Elisabetta Bucciantini, Marco Di Giovanni, Fabrizio Franchi, Lucio Lucchetti, Sara Barbieri Claudio Mariani, Giulia Grande, Piero Rapazzini, Giuseppe Romanelli, Alessandra Marengoni, Luciano Fugazza, Chiara Guerrini, Giovanna De Paduanis, Lucia Iallonardo, Pasquale Palumbo, Giovanni Zuliani, Beatrice Ortolani, Eleonora Capatti, Cecilia Soavi, Lara Bianchi, Daniela Francesconi, Agata Miselli, Teresa Suardi, Cinzia Zaccarini, Gianluca Mirra, Ettore Muti, Renato Bottura, Piero Secreto, Erika Bisio, Marco Cecchettani, Tamara Naldi, Alessandra Pallavicino, Michela Pugliese, Rosaria Cosima lozzo, Giovanni Sgrò Guido Grassi, Raffaella Dell'Oro, Antonio Mannironi, Elisa Giorli, Sara Oberti, Brigida Fierro, Tommaso Piccoli, Fabio Giacalone, Antonella Mandas, Luca Serchisu, Diego Costaggiu, Elisa Pinna, Francesca Orrù, Martina Mannai, Zeno Cordioli, Luca Pelizzari, Roberta Chiloiro, Rosella Cimino, Carmen Ruberto, Pierluigi Dal Santo, Antonino Andriolli, Giuseppe Burattin, Laura Rossi, Fabiana Tezza, Patrizia Crippa, Paola Aloisio, Tiziana Di Monda, Gloria Galbassini, Claudio Ivaldi, Anna Maria Russo, Alberto Pesci, Giulia Suigo, Massimo Zanasi, Giovanni Moniello, Carlo Rostagno, Alessandro Cartei, Gianluca Polidori, Andrea Ungar, Maria Ramona Melis, Eleonora Martellini, Bruno Battiston, Maurizio Berardino, Simona Cavallo, Bruna Lombardi, Pierpaolo D'Íppolito, Angela Furini, Daniele Villani, Clara Raimondi, Massimo Guarneri, Stefano Paolucci, Andrea Bassi, Paola Coiro, Domenico De Angelis, Giovanni Morone, Vincenzo Venturiero, Lorenzo Palleschi, Paolo Raganato, Giuseppina Di Niro, Alessandra Imoscopi, Giancarlo Isaia, Vittoria Tibaldi, Giuliana Bottignole, Elisa Calvi, Carlotta Clementi, Mauro Zanocchi, Luca Agosta, Antonio Criasia, Elena Spertino, Antonella Nortarelli, Giuseppe Provenzano, Pietro Principato, Anita Rizzo, Eleonora Cellura, Angelo Zanghierato, Daniela Mari, Federica Y. Romano, Francesca Rosini, Marta Mansi, Silvia Rossi, Alex Riccardelli, Alfredo Potena, Mihaela Lichii, Tiziana Candiani, William Grimaldi, Emiliano Bertani, Pietro Calogero, Daniela Pinto, Roberto Bernardi, Francesco Nicolino, Caterina Galetti, Alice Gianstefani, Patrizio Odetti, Fiammetta Monacelli, Matteo Prefumo, Giuseppe Paolisso, Maria Rosaria Rizzo, Raffaele Prestano, Anna Maria Dalise, Davide Barra, Livio Dal Bosco, Vincenzo Asprinio, Luciana Dallape, Elisa Perina, Raffaele Antonelli Incalzi, Isaura Rossi Bartoli, Alice Pluderi, Antonella Maina, Elisabetta Pecoraro, Michela Sciarra, Angela Prudente, Lucia Benini, Francesco Levato, Victor Mhiuta, Florin Alius, Diana Davidoaia, Vittorio Giardini, Mattia Garancini,
Claudio Bellamoli, Luciano Terranova, Claudia Bozzini, Paolo Tosoni, Emma Provoli, Luisa Cascone, Andrea Dioli, Gianfranco Ferrarin, Anna Gabutto, Adelmo Bucci, Guido Bua, Sara Fenu, Giovanna Bianchi, Silvia Casella, Valentina Romano, Gloria Belotti, Sabina Cavaliere, Estella Cuni, Nina Merciuc, Rosella Oberti, Katia Colombo, Paolo D'Arcangelo, Nicola Montenegro, Giovanni Galli, Roberto Montanari, Pierpaolo Lamanna, Beatrice Gasperini, Elio Scarpini, Andrea Arighi, Ferdinando D'Amico, Antonino Granata, Carlo Rostagno, Claudia Ranalli, Alessandra Cammilli, Maria Chiara Cavallini, Manola Tricca, Daniela Natella; Gianbattista Guerrini, Anna Maria Scotuzzi, Ferdinando Sozzi, Luigi Valenti, Antonino Chiarello, Monella Monia, Alberto Pilotto, Camilla Prete, Barbara Senesi, Anna Cristina Meta, Enrico Pendenza, Giuseppe Pasqualetti, Antonio Polini, Sara Tognini, Elena Ballino, Giuseppina Dell'Aquila, Pina Maria Gasparrini, Elisabetta Marotti, Monica Migale, Antonia Scrimieri, Gabriele Toigo, Giuliano Ceschia, Alessia Rosso, Chiara Tongiorgi, Cristina Scarpa, Maurizio Pacchioni, Luigino De Dominicis, Eugenio Pucci, Sara Renzi, Elisabetta Cartechini, Giuseppe Barilaro, Pietro Gareri, Francesca Ugenti, Pasquale Romeo, Anna Nardelli, Fulvio Lauretani, Sandra Visioli, llaria Montanari, Francesca Ermini, Antonio Giordano, Giorgio Pigato, Emilio Simeone, Franco Colameco, Antonella Cecamore, Rosa Scurti, Maria Cristina Lupinetti, Mario Barbujani, Beatrice Perazzi, Marina Giampieri, Raffaele Amoruso, Maristella Piccinini, Camilla Ferrari, Claudio Gambetti, Mario Sfrappini, Letizia Semeraro, Rinaldo Striuli, Claudia Mariani, Giuseppe Pelliccioni, Donatella Marinelli, Tommaso Rossi, Martina Pesallaccia, Debora Sabbatini, Beatrice Gobbi, Raffaella Cerqua, Giancarla Tagliani, Elena Schlauser, Luciano Caser, Elisa Caramello, Franca Sandigliano, Giorgio Rosso, Chiara Bendini, Moreno Scevola, Enrico Vitale, Domenico Maugeri, Rosaria Sorace, Massimiliano Anzaldi, Roberto De Gesu, Giuseppe Morrone, Federica Davolio, Andrea Fabbo, Marco Zoli, Paola Forti, Luca Pirazzoli, Elisa Fabbri, Christian Wenter, Ingrid Ruffini, Miriam Insam, Elisabeth Abraham, Christine Kirchlechner, Domenico Cucinotta, Giorgio Basile, Pasquale Parise, Andrea Boccali, Serena Amici, Maurizia Gambacorta, Anna Lasagni, Roberto Lovati, Francesca Giovinazzo, Elzbieta Kimak, Marika Lo Castro, Flavia Mauro, Alessandro De Luca, Giuseppe Sancesario, Alessandro Martorana, Beatrice Scaricamazza, Sofia Toniolo, Francesco Di Lorenzo, Claudio Liguori, Antonino Lasco, Natale Vita, Mirna Giomi, Sergio Dimori, Floriana Forte, Alessandro Padovani, Luca Rozzini, Anna Ceraso, Maria Cottino, Silvia Vitali, Eleonora Marelli, Gabriele Tripi, Salvatore Miceli, Giovanni Urso, Giuseppe Grioni, Giuliana Vezzadini, Giulia Misaggi, Chiara Forlani, Stefano Avanzi, Francesco lemolo, Antonello Giordano, Enzo Sanzaro, Gabriele D'Asta, Maria Proietto, Anna Carnemolla, Grazia Razza, Daniela Spadaro, Marco Bertolotti, Chiara Mussi, Francesca Neviani, Francesca Balestri, Monica Torrini, Giulio Mannarino, Francesca Tesi, Michela Bigolari, Alessia Natale, Simona Grassi, Cinzia Bottaro, Sara Stefanelli, Ugo Bovone, Umberto Tortorolo, Roberto Quadri, Giuseppe Leone, Maria Ponzetto, Paola Frasson, Giorgio Annoni, Adriana Bruni, Roberto Confalonieri, Maurizio Corsi, Daniela Moretti, Fabiola Teruzzi, Simona Umidi, Paolo Caffarra, Federica Barocco, Marco Spallazzi, Paolo Chioatto, Sandra Bortolamei, Lucia Soattin, Giovanni Ruotolo, Alberto Castagna, Marco Bertazzoli, Elisabetta Rota, Annamaria Adobati, Alberto Scarpa, Serena Granziera, Paola Zuccher, Angela Dal Fabbro, Daniela Zara, Ambra Lo Nigro, Lorena Franchetti, Marika Toniolo, Cinzia Marcuzzo, Simonetta Piano, Marco Rollone, Fabio Guerriero, Carmelo Sgarlata, Alessandro Massè, Maurizio Berardino, Simona Cavallo, Giovanni Zatti, Massimiliano Piatti, Jole Graci, Giuseppe Benati, Federica Boschi, Mario Biondi, Nicoletta Fiumi, Sergio M. Locatelli, Sabrina Mauri, Mauro Beretta, Laura Margheritis, Giovanbattista Desideri, Ester Liberatore, Anna Cecilia Carucci, Paolo Bonino, Margherita Caput, Maria Paola Antonietti, Giuseppe Polistena, Franz De la Pierre, Marcello Mari, Paola Massignani, Fabio Tombesi, Fabio Selvaggio, Brunella Verbo, Paolo Bodoni, Niccolò Marchionni, Maria Chiara Cavallini, Tony Sabatini, Eleonora Mussio, Giulia Titoldini, Beatrice Cossu, Sara Fascendini, Cristina Licini, Angela Tomasoni, Massimo Calderazzo, Raffaella Prampolini, Rita Maria Melotti, Albina Lilli, Simona Buda, Marco Adversi, Gabriele Noro, Renato Turco, Maria C. Ubezio, Anna Roberta Mantovani, Maria C. Viola, Carlo Serrati, Maria Infante, Simona Gentile, Viviana D'Ambrosio, Paolo Mazzanti, Cristina Brambilla, Silvia Sportelli, Daniela Quattrocchi, Luigi M. Pernigotti, Cristina Pisu, Francesca Sicuro, Piergiuseppe Zagnoni, Stefania Ghiglia, Massimiliano Mosca, lleana Corazzin, Mariangela Deola, Carlo Adriano Biagini, Francesca Bencini, Claudia Cantini, Elisabetta Tonon, Silvia Pierinelli, Marco Onofrj, Astrid Thomas, Laura Bonanni, Gabriella Cacchiò, Giancarlo Comi, Giuseppe Magnani, Roberto Santangelo, Salvatore Mazzeo, Cristina Barbieri, Liviana Giroldi, Federica Davolio, Fabio Bandini, Marco Masina, Simona Malservisi, Annalena Cicognani, Laura Ricca, Tiziana Tassinari, Davide Brogi, Annalisa Sugo. 


\section{Authors' contributions}

All authors had full access to all of the data in the study and take responsibility for the integrity of the data and the accuracy of the data analysis. GB, AMor, $M M, A B$, and MT conceived and designed the study. GB and SGS acquired the data; $\mathrm{GB}, \mathrm{AM}$ r, SGS, AM, AC, EM, MB, AB, RR, EZ, MM, and MT analyzed and interpreted the data. GB and $A M$ drafted the manuscript, and GB, AMor, SGS, $A M, A C, E M, M B, A B, R R, E Z, M M, A F, N F$, and $M T$ critically revised it for important intellectual content. AM performed the statistical analysis. GB, SDS, and MM provided administrative, technical, or material support. GB supervised the study. All authors agree to be accountable for all aspects of the work in ensuring that questions related to the accuracy or integrity of any part of the work are appropriately investigated and resolved. All authors read and approved the final manuscript.

\section{Competing interests}

The authors declare that they have no competing interests.

\section{Author details}

'School of Medicine and Surgery, University of Milano-Bicocca, Milano, Italy. ${ }^{2}$ Geriatric Unit, San Gerardo University Hospital, Monza, Italy. ${ }^{3}$ Geriatric Research Group, Brescia, Italy. ${ }^{4}$ Department of Rehabilitation and Aged Care "Fondazione Camplani" Hospital, Cremona, Italy. ${ }^{5}$ Department of Clinical and Behavioral Neurology, Neuropsychiatry Laboratory, IRCCS Foundation S Lucia, Roma, Italy. ${ }^{6}$ Redaelli Geriatric Institute, Milan, Italy. ${ }^{7}$ Geriatrics and Geriatric Emergency Care, IRCCS-INRCA, Ancona, Italy. ${ }^{8}$ Research Unit of Medicine of Ageing, Department of Experimental and Clinical Medicine, University of Florence and Azienda Ospedaliero-Universitaria Careggi, Firenze, Italy. ${ }^{9}$ Section of Geriatrics, Città della Salute e della Scienza - Molinette, Torino, Italy. ${ }^{10}$ Medicine and Rehabilitation Department, Istituto Clinico S. Anna, Brescia, Italy. "'Department of Geriatric and Internal Medicine, Poliambulanza Hospital, Brescia, Italy. ${ }^{12}$ Institute of Biomedical Technologies, National Research Council, Segrate (Milan), Italy. ${ }^{13}$ Italian Society of Neurology for Dementia (SINDEM), Siena, Italy. ${ }^{14}$ Geriatric Unit, Department of Neuromotor Physiology, ASMN Hospital, Reggio Emilia, Italy. ${ }^{15}$ Italian Society of Hospital and Community Geriatrics (SIGOT), Roma, Italy. ${ }^{16}$ Department of Translational Medical Sciences, Federico II University of Naples, Naples, Italy. ${ }^{17}$ Salvatore Maugeri Foundation, IRCCS, Scientific Institute of Telese, Telese Terme (BN), Italy. ${ }^{18}$ Italian Society of Gerontology and Geriatrics (SIGG), Florence, Italy. ${ }^{19}$ Tor Vergata, Rome University, Rome, Italy. ${ }^{20}$ Italian Psychogeriatric Association (AIP), Brescia, Italy.

Received: 26 April 2016 Accepted: 23 June 2016 Published online: 18 July 2016

\section{References}

1. American Psychiatric Association. Diagnostic and statistical manual of mental disorders. 5th ed. Arlington, VA: American Psychiatric Association; 2013.

2. Witlox J, Eurelings LS, de Jonghe JF, Kalisvaart KJ, Eikelenboom P, van Gool WA. Delirium in elderly patients and the risk of postdischarge mortality, institutionalization, and dementia: a meta-analysis. JAMA. 2010;30:443-51.

3. Davis DH, Skelly DT, Murray C, Hennessy E, Bowen J, Norton S, Brayne C, Rahkonen T, Sulkava R, Sanderson DJ, Rawlins JN, Bannerman DM, MacLullich AMJ, Cunningham C.. Worsening cognitive impairment and neurodegenerative pathology progressively increase risk for delirium. Am J Geriatr Psychiatry. 2015;23:403-15.

4. Inouye SK, Westendorp RG, Saczynski JS. Delirium in elderly people. Lancet. 2014;383:911-22.

5. Bellelli G, Mazzola P, Morandi A, Bruni A, Carnevali L, Corsi M, Zatti G, Zambon A, Corrao G, Olofsson B, Gustafson Y, Annoni G. Duration of postoperative delirium is an independent predictor of 6-month mortality in older adults after hip fracture. J Am Geriatr Soc. 2014;62:1335-40.

6. Leslie DL, Marcantonio ER, Zhang Y, Leo-Summers L, Inouye SK. One-year health care costs associated with delirium in the elderly population. Arch Intern Med. 2008;168:27-32.

7. Development of EC-oF. OECD health data. Paris: Organisation for Economic Co-operation and Development; 2012.

8. Morandi A, Lucchi E, Turco R, Morghen S, Guerini F, Santi R, Gentile S, Meagher D, Voyer P, Fick DM, Schmitt EM, Inouye SK, Trabucchi M, Bellelli G. Delirium superimposed on dementia: A quantitative and qualitative evaluation of informal caregivers and health care staff experience. J Psychosom Res. 2015;79:272-80.
9. Morandi A, Lucchi E, Turco R, Morghen S, Guerini F, Santi R, Gentile S, Meagher D, Voyer P, Fick D, Schmitt EM, Inouye SK, Trabucchi M, Bellelli G. Delirium superimposed on dementia: A quantitative and qualitative evaluation of patient experience. J Psychosom Res. 2015;79: $281-7$.

10. Lin RY, Heacock LC, Bhargave GA, Fogel JF. Clinical associations of delirium in hospitalized adult patients and the role of on admission presentation. Int J Geriatr Psychiatry. 2010;25:1022-9.

11. Clegg A, Westby M, Young JB. Under-reporting of delirium in the NHS. Age Ageing. 2011;40:283-6.

12. Bellelli G, Nobili A, Annoni G, Morandi A, Djade CD, Meagher DJ, Maclullich AM, Davis D, Mazzone A, Tettamanti M, Mannucci PM; REPOSI (REgistro POliterapie SIMI) Investigators. Under-detection of delirium and impact of neurocognitive deficits on in-hospital mortality among acute geriatric and medical wards. Eur J Intern Med. 2015;26:696-704.

13. Bellelli G, Morandi A, Zanetti E, Bozzini M, Lucchi E, Terrasi M, Trabucchi M, AIP delirium study group. Recognition and management of delirium among doctors, nurses, physiotherapists, and psychologists: an Italian survey. Int Psychogeriatr. 2014;26:2093-102.

14. Collins N, Blanchard MR, Tookman A, Sampson EL. Detection of delirium in the acute hospital. Age Ageing. 2010;39:131-5.

15. Brown TM, Boyle MF. Delirium. BMJ. 2002;325:644-7.

16. Kakuma R, du Fort GG, Arsenault L, Perrault A, Platt RW, Monette J, Moride $Y$, Wolfson C. Delirium in older emergency department patients discharged home: effect on survival. J Am Geriatr Soc. 2003;51:443-50.

17. Tabet N, Hudson S, Sweeney V, Sauer J, Bryant C, Macdonald A, Howard R. An educational intervention can prevent delirium on acute medical wards. Age Ageing. 2005;34:152-6.

18. Hshieh TT, Yue J, Oh E, Puelle M, Dowal S, Travison T, Inouye SK. Effectiveness of multicomponent nonpharmacological delirium interventions: a meta-analysis. JAMA Intern Med. 2015;175:512-20.

19. Abraha I, Trotta F, Rimland JM, Cruz-Jentoft A, Lozano-Montoya I, Soiza RL, Pierini V, Dessì Fulgheri P, Lattanzio F, O'Mahony D, Cherubini A. Efficacy of non-pharmacological interventions to prevent and treat delirium in older patients: a systematic overview. The SENATOR project ONTOP Series. PLOS One. 2015;10:e0123090.

20. Greysen SR. Delirium and the "know-do" gap in acute care for elders. JAMA Intern Med. 2015;175:521-2.

21. Bellelli G, Magnifico F, Trabucchi M. Outcomes at 12 months in a population of elderly patients discharged from a rehabilitation unit. J Am Med Dir Assoc. 2008;9:55-64.

22. Morandi A, Bellelli G, Vasilevskis EE, Turco R, Guerini F, Torpilliesi T, Speciale S, Emiliani V, Gentile S, Schnelle J, Trabucchi M. Predictors of rehospitalization among elderly patients admitted to a rehabilitation hospital: the role of polypharmacy, functional status, and length of stay. J Am Med Dir Assoc. 2013;14:761-7.

23. Eeles EM, Hubbard RE, White SV, O'Mahony MS, Savva GM, Bayer AJ. Hospital use, institutionalisation and mortality associated with delirium. Age Ageing. 2010;39:470-5.

24. Adamis D, Treloar A, Darwiche FZ, Gregson N, Macdonald AJ, Martin FC. Associations of delirium with in-hospital and in 6-months mortality in elderly medical inpatients. Age Ageing. 2007;36:644-9.

25. Iseli RK, Brand C, Telford M, LoGiudice D. Delirium in elderly general medical inpatients: a prospective study. Intern Med J. 2007;37:806-11.

26. Ryan DJ, O'Regan NA, Caoimh RO, Clare J, O'Connor M, Leonard M, McFarland J, Tighe S, O'Sullivan K, Trzepacz PT, Meagher D, Timmons S. Delirium in an adult acute hospital population: predictors, prevalence and detection. BMJ Open. 2013, 3. doi: 10.1136/bmjopen-2012-001772.

27. Young RS, Arseven A. Diagnosing delirium. JAMA. 2010;304:2125-56.

28. Inouye SK, Foreman MD, Mion LC, Katz KH, Cooney Jr LM. Nurses' recognition of delirium and its symptoms: comparison of nurse and researcher ratings. Arch Intern Med. 2001;161:2467-73.

29. Bellelli G, Morandi A, Davis DH, Mazzola P, Turco R, Gentile S, Ryan T, Cash H, Guerini F, Torpilliesi T, Del Santo F, Trabucchi M, Annoni G, MacLullich AM. Validation of the 4AT, a new instrument for rapid delirium screening: a study in 234 hospitalised older people. Age Ageing. 2014;43:496-502.

30. Lo Scalzo A, Donatini A, Orzella L, Cicchetti A, Profili S, Maresso A. Italy, health system review. Health Syst Transit. 2009;11(6):1-216.

31. Katz S, Downs TD, Cash HR, Grotz RC. Progress in development of the index of ADL. Gerontologist. 1970;10:20-30. 
32. Charlson ME, Pompei P, Ales KL, MacKenzie CR. A new method of classifying prognostic comorbidity in longitudinal studies: development and validation. J Chronic Dis. 1987;40:373-83.

33. Meagher DJ, Moran M, Raju B, Gibbons D, Donnelly S, Saunders J, Trzepacz PT. Motor symptoms in 100 patients with delirium versus control subjects: comparison of subtyping methods. Psychosomatics. 2008:49:300-8.

34. Meagher DJ, Leonard M, Donnelly S, Conroy M, Adamis D, Trzepacz PT. A longitudinal study of motor subtypes in delirium: frequency and stability during episodes. J Psychosom Res. 2012;72:236-41.

35. Godfrey A, Leonard M, Donnelly S, Conroy M, Olaighin G, Meagher D. Validating a new clinical subtyping scheme for delirium with electronic motion analysis. Psychiatry Res. 2010;178:186-90.

36. Siddiqi N, House AO, Holmes JD. Occurrence and outcome of delirium in medical in-patients: a systematic literature review. Age Ageing. 2006:35:350-64.

37. de Rooij SE, van Munster BC, Korevaar JC, Levi M. Cytokines and acute phase response in delirium. J Psychosom Res. 2007;62:521-5.

38. White S, Calver BL, Newsway V, Wade R, Patel S, Bayer A, et al. Enzymes of drug metabolism during delirium. Age Ageing. 2005;34:603-8.

39. Wierenga PC, Buurman BM, Parlevliet JL, van Munster BC, Smorenburg SM, Inouye SK, et al. Association between acute geriatric syndromes and medication-related hospital admissions. Drugs Aging. 2012;29:691-9.

40. Buurman BM, Hoogerduijn JG, de Haan RJ, Abu-Hanna A, Lagaay AM, Verhaar HJ, Schuurmans MJ, Levi M, de Rooij SE. Geriatric conditions in acutely hospitalized older patients: prevalence and one-year survival and functional decline. PLoS One. 2011:6:e26951.

41. Pitkala KH, Laurila JV, Strandberg TE, Tilvis RS. Prognostic significance of delirium in frail older people. Dement Geriatr Cogn Disord. 2005;19:158-63.

42. Zakriya K, Sieber FE, Christmas C, Wenz Sr JF, Franckowiak S. Brief postoperative delirium in hip fracture patients affects functional outcome at three months. Anesth Analg. 2004;98:1798-802.

43. Krogseth M, Wyller TB, Engedal K, Juliebo V. Delirium is an important predictor of incident dementia among elderly hip fracture patients. Dement Geriatr Cogn Disord. 2011;31:63-70.

44. Juliebo V, Bjoro K, Krogseth M, Skovlund E, Ranhoff AH, Wyller TB. Risk factors for preoperative and postoperative delirium in elderly patients with hip fracture. J Am Geriatr Soc. 2009;57:1354-61.

45. Landreville P, Voyer P, Carmichael PH. Relationship between delirium and behavioral symptoms of dementia. Int Psychogeriatr. 2013;25:635-43.

46. Inouye SK. Predisposing and precipitating factors for delirium in hospitalized older patients. Dement Geriatr Cogn Disord. 1999;10:393-400.

47. Fitzgerald J, O'Regan N, Adamis D, Timmons S, Dunne C, Trzepacz P, Meagher D. Concordance between the delirium motor subtyping scale (DMSS) and the abbreviated version (DMSS-4) over longitudinal assessment in elderly medical inpatients. Int Psychogeriatr. 2016;28:845-51.

48. Kiely DK, Jones RN, Bergmann MA, Marcantonio ER. Association between psychomotor activity delirium subtypes and mortality among newly admitted post-acute facility patients. J Gerontol A Biol Sci Med Sci. 2007;62:174-9.

49. Meagher DJ, Morandi A, Inouye SK, Ely W, Adamis D, Maclullich AJ, Rudolph JL, Neufeld K, Leonard M, Bellelli G, Davis D, Teodorczuk A, Kreisel S, Thomas C, Hasemann W, Timmons S, O'Regan N, Grover S, Jabbar F, Cullen W, Dunne C, Kamholz B, Van Munster BC, De Rooij SE, De Jonghe J, Trzepacz PT. Concordance between DSM-IV and DSM-5 criteria for delirium diagnosis in a pooled database of 768 prospectively evaluated patients using the delirium rating scale-revised-98. BMC Med. 2014;30:12-164. doi:10.1186/s12916-014-0164-8.

50. Morandi A, Davis D, Taylor JK, Bellelli G, Olofsson B, Kreisel S, Teodorczuk A, Kamholz B, Hasemann W, Young J, Agar M, de Rooij SE, Meagher D, Trabucchi M, MacLullich AM. Consensus and variations in opinions on delirium care: a survey of European delirium specialists. Int Psychogeriatr. 2013:25:2067-75.

51. Kuladee S, Prachason T. Development and validation of the Thai version of the 4 'A's Test for delirium screening in hospitalized elderly patients with acute medical illnesses. Neuropsychiatr Dis Treat. 2016;24(12):437-43.

52. Lees R, Corbet $\mathrm{S}$, Johnston C, Moffitt E, Shaw G, Quinn TJ. Test accuracy of short screening tests for diagnosis of delirium or cognitive impairment in an acute stroke unit setting. Stroke. 2013;4:3078-83.

\section{Submit your next manuscript to BioMed Central and we will help you at every step:}

- We accept pre-submission inquiries

- Our selector tool helps you to find the most relevant journal

- We provide round the clock customer support

- Convenient online submission

- Thorough peer review

- Inclusion in PubMed and all major indexing services

- Maximum visibility for your research

Submit your manuscript at www.biomedcentral.com/submit 